Article

\title{
Constitutive Expression of Arabidopsis Senescence Associated Gene 101 in Brachypodium distachyon Enhances Resistance to Puccinia brachypodii and Magnaporthe oryzae
}

\author{
Ning Wang ${ }^{1,2,+}$, Na Song ${ }^{1,+}$, Zejun Tang ${ }^{1}$, Xiaojie Wang ${ }^{2}$, Zhensheng Kang ${ }^{2}{ }^{\mathbb{D}}$, \\ Liangying Dai ${ }^{1, *}$ and Bing Wang ${ }^{1, *}$ \\ 1 Hunan Provincial Key Laboratory for Biology and Control of Plant Diseases and Insect Pests and College of \\ Plant Protection, Hunan Agricultural University, Changsha 410128, Hunan, China; \\ wangning@nwafu.edu.cn (N.W.); chinasong86@126.com (N.S.); Tangzj516@126.com (Z.T.) \\ 2 State Key Laboratory of Crop Stress Biology for Arid Areas and College of Plant Protection, Northwest A\&F \\ University, Yangling 712100, Shaanxi, China; wangxiaojie@nwafu.edu.cn (X.W.); \\ kangzs@nwsuaf.edu.cn (Z.K.) \\ * Correspondence: daily@hunau.net (L.D.); zhufu861986@126.com (B.W.) \\ + These authors contributed equally to the work.
}

Received: 19 August 2020; Accepted: 1 October 2020; Published: 6 October 2020

\begin{abstract}
Brachypodium distachyon, as an effective model of cereal grains, is susceptible to most destructive cereal pathogens. Senescence associated gene 101 (SAG101) has been studied extensively in Arabidopsis. SAG101 is one of the important regulators of plant immunity. However, no homologous genes of AtSAG101 were found in B. distachyon. In this study, the AtSAG101 gene was transformed into $B$. distachyon. Three transgenic plant lines containing the AtSAG101 gene were confirmed by PCR and GUS gene activity. There were fewer Puccinia brachypodii urediospores in the AtSAG101-overexpressing plants compared to wild type plants. P. brachypodii biomass was obviously decreased in AtSAG101 transgenic plants. The length of infection hyphae and infection unit areas of $P$. brachypodii were significantly limited in transgenic plants. Moreover, there were small lesions in AtSAG101 transgenic plants challenged by Magnaporthe oryzae. Salicylic acid accumulation was significantly increased, which led to elevated pathogenesis-related gene expression in transgenic B. distachyon inoculated by $P$. brachypodii or M. oryzae compared to wild type plants. These results were consistent with infected phenotypes. Overexpression of AtSAG101 in B. distachyon caused resistance to M. oryzae and P. brachypodii. These results suggest that AtSAG101 could regulate plant resistance in B. distachyon.
\end{abstract}

Keywords: Senescence Associated Gene 101; salicylic acid; overexpression; Puccinia brachypodii; light microscopy

\section{Introduction}

Plants are continually threatened by a wide variety of potential pathogens in the environment. To cope with pathogens, plants have evolved multiple defense mechanisms to avoid or limit infection [1]. Plants produce an inducible hormone to prevent pathogen invasion and reproduction. Salicylic acid (SA) is a common signal that is essential for resisting pathogens [2]. Salicylic acid (SA) accumulation induces the basal defense or plant resistance $(R)$ gene-pathogen avirulence gene interactions, which induce immunity when host tissues respond to fungi pathogen invasion. An important role of SA is to induce pathogenesis-related (PR) genes expression [3].

Senescence associated gene 101 (SAG101), a 3 lipase-like defense regulator, is an essential component of plant basal resistance against pathogenic strains [4]. SAG101 regulates the production of 
SA to limit pathogen growth. In Arabidopsis, SAG101 is required for plant resistance to Pseudomonas syringae pv. tomato strain DC3000 [5]. Moreover, SAG101 is necessary for R-mediated resistance to turnip crinkle virus [6]. Recently, it has been reported that SAG101a is required for Xanthomonas campestris pv. vesicatoria effector protein XopQ-induced resistance responses in Nicotiana benthamiana [7].

Cereal grains, such as rice and wheat, provide over $50 \%$ of dietary proteins and calories for people [8]. Cereal production is seriously limited and impacted by plant diseases. Brachypodium distachyon (B. distachyon) is an effective model for studying monocot species due to its small genome size, diploid inheritance, a short life-cycle, and simple growth requirements [9]. Due to its close evolutionary relationships to cereal grains, including wheat and rice, B. distachyon facilitates the research of cereal crop grass species in response to different environmental stresses, including of biotic stress [10].

B. distachyon is susceptible to many important cereal pathogens. Magnaporthe oryzae (rice blast) is the top fungal plant pathogen, which can cause devastating effects on rice [11]. The development and disease progression of $M$. oryzae (Guy11) fungus in B. distachyon and rice are similar [12]. M. oryzae-B. distachyon is the compatible interaction, which has emerged as a resource for studies on susceptible interactions [13]. Rust pathogens, namely, Puccinia striiformis f. sp. tritici (Pst, stripe rust), P. graminis f. sp. tritici (Pgt, responsible for wheat stem rust), and P. triticina (Pt, leaf rust), are third in the list of top 10 fungal plant pathogens, which are major disease threats to wheat production [11]. Puccinia brachypodii can infect many Brachypodium species, including B. distachyon. P. brachypodii is closely related to these three rust pathogens in wheat based on phylogenetic studies [14]. The compatible interaction between $B$. distachyon and $P$. brachypodii is being development as a model to study wheat and rust pathogen interactions.

AtSAG101 is an important component of the plant basal resistance against pathogens in Arabidopsis. However, we did not identify homologous genes of AtSAG101 in B. distachyon. In this study, we transformed AtSAG101 into B. distachyon and showed that overexpression of AtSAG101 in B. distachyon induced resistance to P. brachypodii and M. oryzae. These results inferred that AtSAG101 confers resistance to pathogens in $B$. distachyon.

\section{Results}

\subsection{Overexpression of AtSAG101 in B. distachyon}

There is considerable knowledge of the AtSAG101 gene and its ability to enhance resistance to pathogens [5,7]. However, we did not find homologous genes of AtSAG101 in B. distachyon. In this study, AtSAG101 was transformed into B. distachyon. AtSAG101 transgenic plants were identified by PCR. Three transgenic plant lines were successfully identified to contain the AtSAG101 gene, named Lines 2-1, 3-2 and 5-2 (Figure S1). Furthermore, we analyzed $\beta$-glucuronidase (GUS) gene expression and activity in transgenic plants (Figure 1). Three transformed lines showed GUS activity, but wild type showed no detectable GUS phenotype using histological staining. These results demonstrated that AtSAG101 was successfully transformed into B. distachyon. 


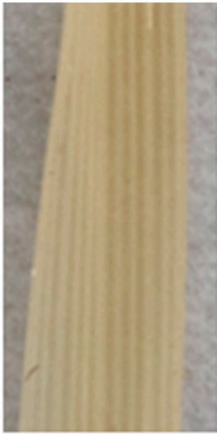

WT
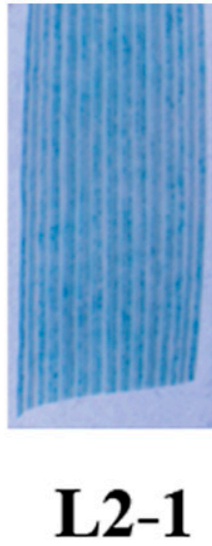

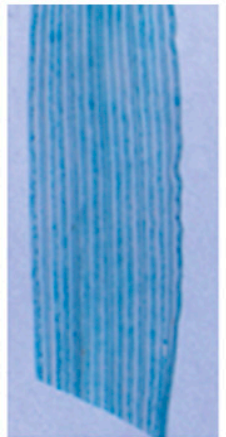

L3-2

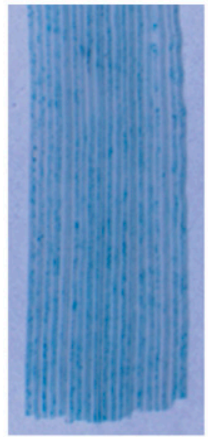

L5-2

Figure 1. Confirmation of Arabidopsis senescence associated gene 101 (AtSAG101) in transgenic Brachypodium distachyon. Histochemical staining of the $\beta$-glucuronidase (GUS) gene in AtSAG101 transgenic $B$. distachyon. WT, wild type plants; L2-1, L3-2 and 5-2, transgenic $B$. distachyon plants.

\subsection{AtSAG101 Transgenic Plants Induce Resistance to P. brachypodii}

To test the function of AtSAG101 during B. distachyon-P. brachypodii interactions, AtSAG101 transgenic plants were inoculated by the F-CO isolate of P. brachypodii. The B. distachyon Bd21-3 genotype is susceptible to $P$. brachypodii. Wild type (WT) plants produced numerous urediniospores 15 dpi after inoculation with F-CO. Compared to WT leaves, limited urediospore production was observed on leaves of AtSAG101 transgenic plants (Figure 2A). P. brachypodii biomass was used to further verify phenotypes. P. brachypodii biomass was obviously decreased in the leaves of AtSAG101 transgenic plants compared to WT plants (Figure 2B).

A

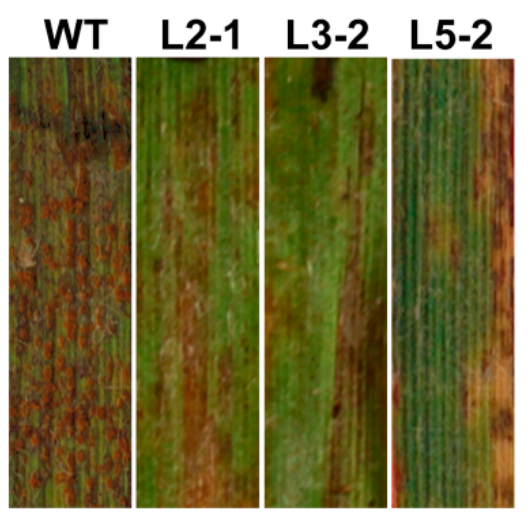

\section{B}

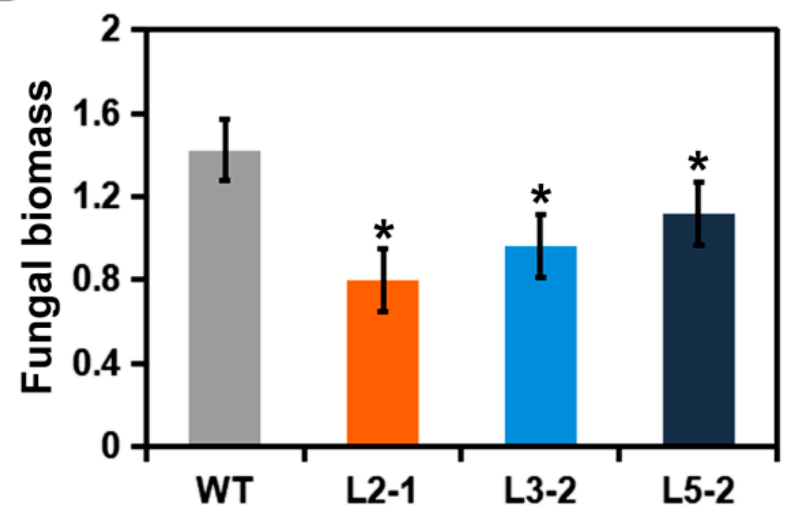

Figure 2. AtSAG101 transgenic plants enhance resistance to Puccinia brachypodii. (A) Phenotypic changes in leaves of AtSAG101 transgenic plants challenged with P. brachypodii. (B) Biomass of P. brachypodii. Significant differences were determined using Student's $t$-test: ${ }^{*}, p<0.05$. WT, wild type plants; L2-1, L3-2 and 5-2, transgenic B. distachyon plants.

Furthermore, histological changes in AtSAG101 transgenic plants inoculated with F-CO were observed (Figure 3A). Length of infection hyphae (IH) and infection unit areas were observed and calculated. At $48 \mathrm{~h}$ after infection with the F-CO isolate, IH growth was significantly limited in AtSAG101 transgenic plants (Figure $3 \mathrm{~B}$ ). Moreover, the $P$. brachypodii infection unit area was significantly reduced $(P<0.05)$ in AtSAG101 transgenic B. distachyon leaves at 120 hpi compared to WT leaves (Figure 3C). 
A

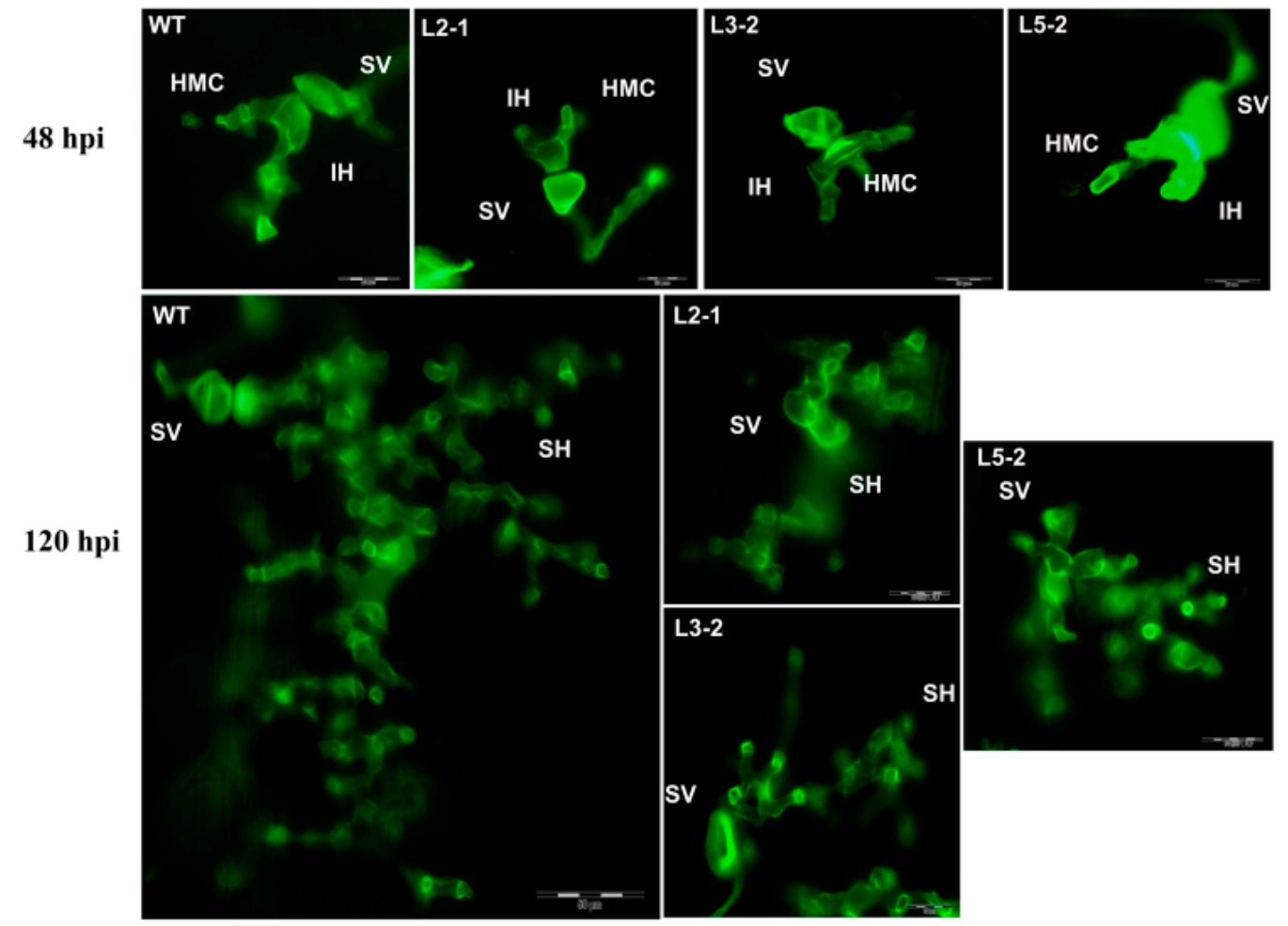

B

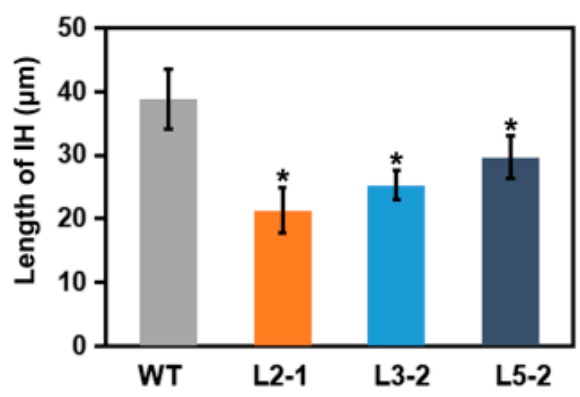

C

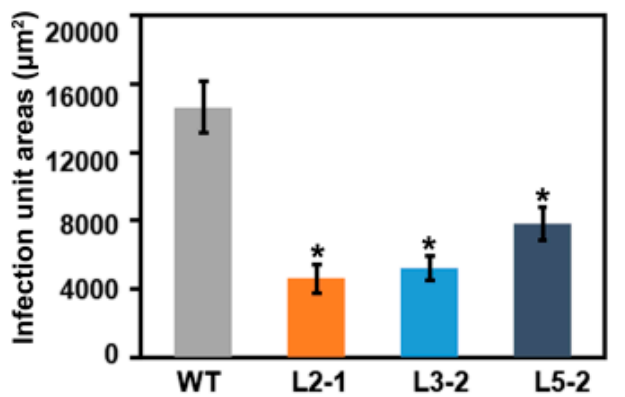

Figure 3. Histological determination of fungal growth in AtSAG101 transgenic plants. (A) Histological observation of fungal development. (B) Length of infection hyphae was significantly reduced. (C) A significant decrease in infection unit areas. WT, wild type plants; L2-1, L3-2 and 5-2, transgenic B. distachyon plants; IH, infection hyphae; SH, secondary hyphae; HMC, haustorial mother cells; SV, substomatal vesicle (24 hpi, bar $=20 \mu \mathrm{m} ; 120 \mathrm{hpi}$, bar $=50 \mu \mathrm{m}) ;{ }^{*}, p<0.05$.

\subsection{SA Levels Are Increased in AtSAG101-Overexpressing B. distachyon Leaves}

SAG101 induces the production of SA to limit pathogen growth. To test a possible role of AtSAG101 in regulating SA, we examined SA levels in AtSAG101 transgenic B. distachyon leaves (Figure 4A). SA accumulation was slightly higher in transgenic $B$. distachyon leaves compared to WT plants when unchallenged by P. brachypodii. At $24 \mathrm{hpi}$, SA accumulation was obviously increased (the range from 20.69 to $26.39 \mathrm{ng} / \mathrm{g}$ ) in transgenic plants infected with P. brachypodii. However, there was no obvious change in SA accumulation in WT plants challenged by P. brachypodii, indicating a different response to that shown earlier in WT plants challenged by P. brachypodii.

To determine if the expression levels of defense-related genes were affected in the AtSAG101 transgenic plants after challenge by $P$. brachypodii, we selected $P R$ genes for quantitative RT-PCR (qRT-PCR) analysis. The expression levels of $P R 1$, and $P R 5$ were significantly increased in transgenic B. distachyon leaves infected with $P$. brachypodii at 24,48 , and 120 hpi (Figure 4B). 
A

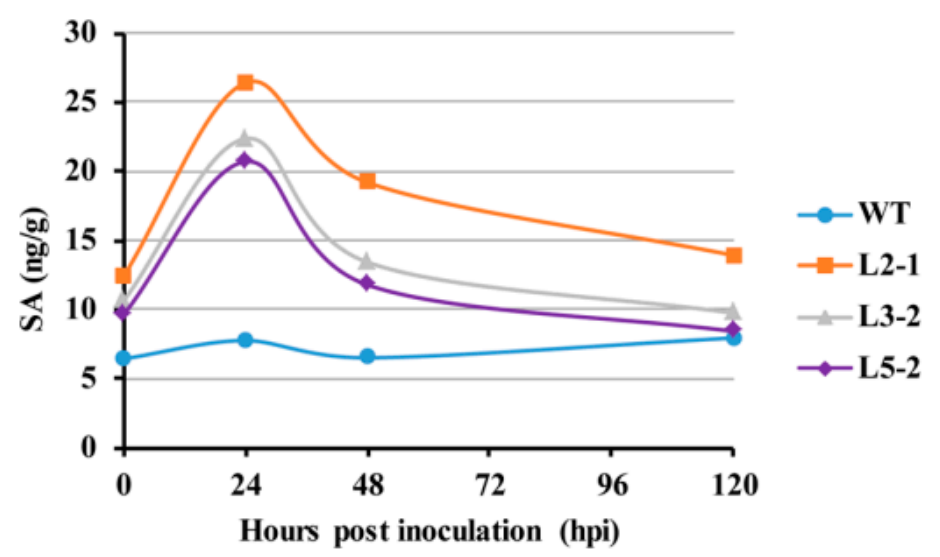

B

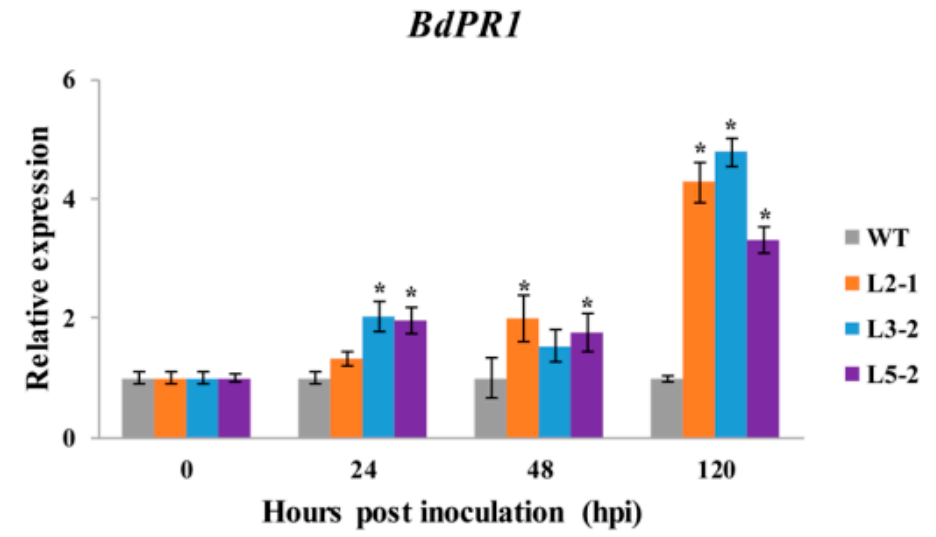

\section{BdPR5}

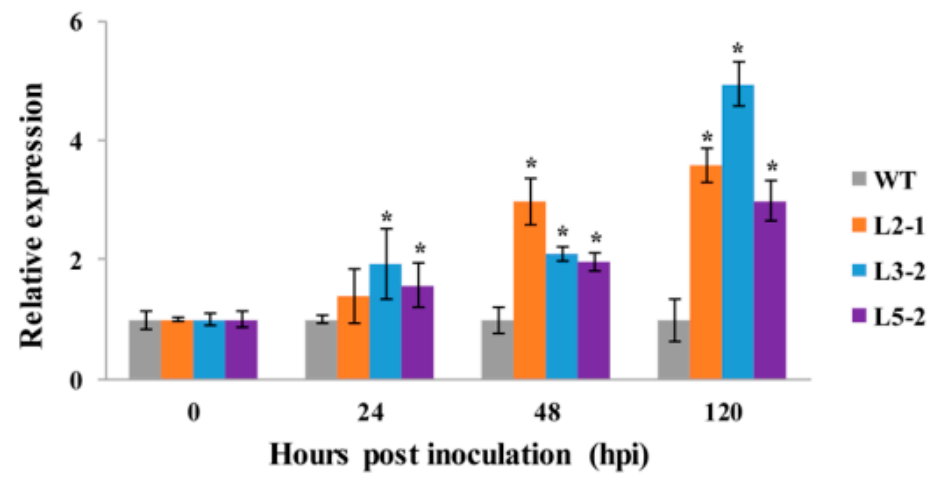

Figure 4. Detection of SA levels and defense-related genes in AtSAG101 transgenic plants infected with Puccinia brachypodii. (A) SA accumulation in AtSAG101 transgenic leaves. (B) Transcript levels of defense-related genes in AtSAG101 transgenic leaves challenged with P. brachypodii. SA, salicylic acid; ng/mg, SA accumulation (ng) per fresh leaf weight (mg); WT, wild type plants; L2-1, L3-2 and 5-2, transgenic $B$. distachyon plants; $B$. distachyon (Bd) PR1 gene (upper panel) and BdPR5 gene (lower panel). *, $p<0.05$.

\subsection{AtSAG101 Transgenic Plants Produce Resistance to Magnaporthe oryzae}

Magnaporthe oryzae is an important rice fungus that can infect $B$. distachyon. In this study, we also inoculated AtSAG101 transgenic plants with M. oryzae to test the function of AtSAG101 during 
B. distachyon-M. oryzae interactions (Figure 5A). AtSAG101 transgenic plants showed resistance to disease symptoms with small lesions, while large disease lesions were observed in WT plants at 5 dpi. Moreover, there was a 2.2-fold peak in SA accumulation in transgenic B. distachyon leaves challenged by M. oryzae at 24 hpi (Figure 5B). However, there was no obvious change in WT plants challenged with $M$. oryzae. The expression levels of $P R 1$ and $P R 5$ were significantly induced in transgenic plants challenged by $M$. oryzae at 24, 48, and 96 hpi (Figure 5C).

A

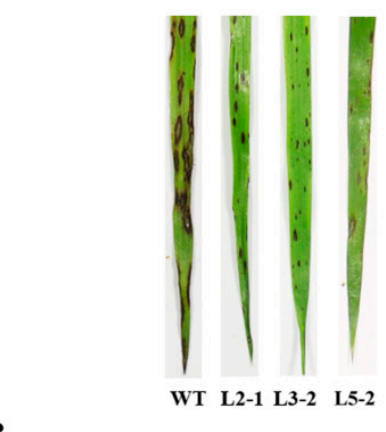

B

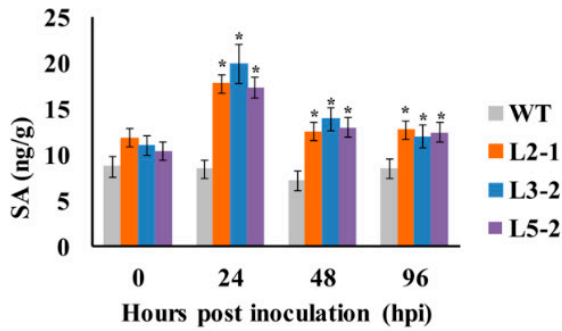

C
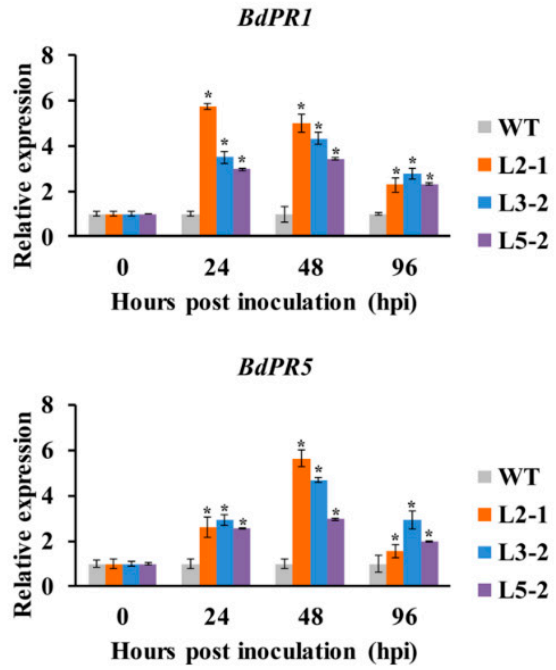

Figure 5. AtSAG101 transgenic plants produce resistance to Magnaporthe oryzae. (A) Phenotypic changes in leaves of AtSAG101 transgenic plants challenged with M. oryzae. (B) Salicylic acid (SA) accumulation in AtSAG101 transgenic leaves infected with M. oryzae. (C) qRT-PCR detection of $P R$ gene expression in AtSAG101-overexpressing B. distachyon leaves inoculated with M. oryzae. PR, pathogenesis-related gene; WT, wild type plants; L2-1, L3-2 and 5-2, transgenic B. distachyon plants; B. distachyon (Bd) PR1 gene (upper panel) and BdPR5 gene (lower panel). Significant differences were determined using Student's $t$-test: ${ }^{*}, p<0.05$. 


\section{Discussion}

Plants utilize multilayered defense strategies to limit or resist pathogen infection [1]. The lipase-like proteins, enhanced disease susceptibility1 (EDS1), SAG101 and phytoalexin deficient 4 (PAD4), are important regulators of plant immunity [15,16]. EDS1 and PAD4 are present in monocots and eudicots according to phylogenetic analysis, whereas SAG101 is not found in monocot genomes $[17,18]$. We also did not find homologous genes of AtSAG101 in the B. distachyon genome, thereby inferring evolution of SAG101 in different plants. In this study, we transformed the AtSAG101 gene into B. distachyon to determine if overexpression of the AtSAG101 gene produces resistance to different pathogens. Three transgenic plant lines (Lines 2-1, 3-2 and 5-2) were successfully transformed plants containing the AtSAG101 gene, which was confirmed by PCR and the GUS phenotype.

SAG101 is an essential component of plant basal resistance. In Arabidopsis, SAG101 plays important roles in resistance to bacterial pathogens and turnip crinkle virus [6]. In N. benthamiana, NbSAG101a is involved in resistance to Xanthomonas campestris pv. Vesicatoria [7]. AtSAG101 induces resistance activity in N. benthamiana, inferring it may enhance resistance in other plants [19]. In this study, we demonstrated that overexpression of the AtSAG101 gene produces resistance to P. brachypodii and M. oryzae. After inoculation with the P. brachypodii F-CO isolate, limited urediospore production was observed on AtSAG101 transgenic plant leaves. The biomass and detailed histological analysis confirmed that IH and infection unit areas of P. brachypodii were inhibited in AtSAG101 transgenic plants. These results were consistent with infected phenotypes. Moreover, AtSAG101 transgenic plants showed resistance to disease symptoms with small disease lesions compared to WT plants during B. distachyon-M. oryzae interactions. These results indicated that AtSAG101 may regulate immune signaling in different plants to multiply pathogenic strains.

$\mathrm{SA}$, as an important plant defense signalling component, takes part in resistance to biotrophic pathogens. PAD4 is a key gene involved in pathogen-induced SA accumulation [20]. SAG101, which is thought to serve as a substitute for PAD4, functions in plant resistance [21]. There are different roles of PAD4 and SAG101 in regulating SA. Previously, we identified that SA accumulation is increased in AtPAD4 transgenic B. distachyon resistance to P. brachypodii [22]. However, SA accumulation is not obviously changed in WT plants and AtPAD4 transgenic plants lacking P. brachypodii infection. In this study, the SA levels were higher in AtSAG101 transgenic plants compared to WT plants. Moreover, SA accumulation was obviously increased when transgenic plants were challenged with P. brachypodii and M. oryzae. These results suggested that AtSAG101 transgenic plants enhance resistance to P. brachypodii and M. oryzae by increasing SA accumulation. We also found that PAD4 and SAG101 play different roles in mediating SA accumulation in B. distachyon. The resistance was not effectively activated in B. distachyon WT plants challenged with P. brachypodii and M. oryzae. SAG101 is not required for the SA-mediated induction of $R$ genes [6]. We inferred overexpression of AtSAG101 can directly activate SA pathway in $B$. distachyon to involve in plant immunity, which is independent on the SA-mediated induction of $R$ genes. However, the complex mechanism of AtSAG101 increasing SA accumulation needs to be studied further.

SA accumulation induces the expression of defense genes in response to virulent pathogens [23]. For example, the TaMAPK4 (a wheat MAP kinase 4) gene is involved in regulating SA accumulation. In TaMAPK4 knockdown plants, the expression levels of TaPR1 and TaPR5 are obviously reduced [24]. In this study, we found that the expression levels of PR1 and PR5 were significantly induced in AtSAG101 transgenic plants challenged by P. brachypodii and M. oryzae. Therefore, these results suggested that the accumulation of PR proteins may lead to enhanced disease resistance in AtSAG101-overexpressing plants.

In summary, three transgenic plant lines were successfully transformed to contain the AtSAG101 gene. We showed that overexpression of AtSAG101 in B. distachyon enhances resistance to M. oryzae and P. brachypodii. SA accumulation was increased in AtSAG101 transgenic plants challenged with B. distachyon, which lead to increased PR gene expression. Overexpression of AtSAG101 can directly activate plant defense. The results suggested that broad-spectrum genes can be selected in the process 
of breeding. In particular, those downstream resistance factors which are directly involved in regulating the resistance pathway are valuable candidates in disease resistance breeding.

\section{Materials and Methods}

\subsection{Plant and Fungal Materials}

In this study, the B. distachyon Bd21-3 genotype, P. brachypodii F-CO isolate and M. oryzae RO1-1 isolate were used. Bd21-3 is susceptible to RO1-1 and F-CO. B. distachyon was grown in a $22{ }^{\circ} \mathrm{C}$ growth chamber with $16 \mathrm{~h}(\mathrm{~h})$ of light and $8 \mathrm{~h}$ of dark. Three seedlings were grown $8 \mathrm{~cm}$ diameter pots with medium, and 5 weeks old plants were inoculated with F-CO. Each treatment contains WT and three different transgenic lines, three plants for each line. Parallel mock inoculations were performed using tap water. Inoculation and incubation of F-CO followed the procedures as previously described [22]. Inoculated leaves were harvested at $0,24,48$ and $96 \mathrm{~h}$ post inoculation (hpi). The inoculation results were evaluated at $15 \mathrm{dpi}$.

Five-week-old seedlings were challenged with $M$. oryzae spore $\left(1 \times 10^{5}\right.$ spores $\left.\mathrm{mL}^{-1}\right)$ by spraying. Seedlings inoculated by RO1-1 were kept in a humid chamber at $28^{\circ} \mathrm{C}$. Disease symptoms were evaluated at $5 \mathrm{dpi}$. Three independent biological replications were performed for each treatment.

\subsection{Gene Cloning and Agrobacterium Transformation}

Total RNA of $A$. thaliana was extracted using the TrizolTM Reagent (Invitrogen, Carlsbad, CA) following the manufacturer's instructions. To synthesize cDNA from RNA, a Revert Aid First-strand cDNA synthesis kit from Fermentas (www.thermosscientific.com/fermentas) was used. The AtSAG101 gene (GenBank accession At5g14930, coding sequences without stop codon) was cloned from Arabidopsis leaves. A1611 bp PCR product was inserted into the pU1301 vector, which contains ubiquitin promotor and the reporter gene $\beta$-glucuronidase (GUS). The primers used for plasmid construction in the present study are listed in Supplementary Table S1. The pU1301- AtSAG101 vector was constructed for the transgenic plants using the Agrobacterium AGL1. All constructs were verified by sequencing and double digestion, and they were then transformed into B. distachyon following the procedure of Vogel [25]. Three independent homozygous T3 lines with a high expression level of AtSAG101 were selected for further study.

\subsection{Histochemical Staining}

Histochemical staining of leaves to detect GUS gene expression was conducted as previously described [24], except no chloramphenicol was used in the stain. Leaves were transferred into microtiter wells containing $500 \mu \mathrm{L}$ of GUS staining solution (10 mM EDTA, $100 \mathrm{mM}$ Na phosphate at $\mathrm{pH}$ 7, $1 \mathrm{mg} / \mathrm{mL}$ of X-Gluc, and $0.1 \%$ Triton X-100). Stained leaves were cleared in $95 \%$ ethanol to visualize localized staining. Sectioned samples were prepared for photography.

\subsection{Endogenous SA Level Analysis}

B. distachyon mutant and WT plant SA levels were analyzed by HPLC-MS [25]. The SA extraction was performed as previously described [22]. $250 \mathrm{mg}$ of the frozen tissue was extracted and quantitated for SA. SA was extracted with $\mathrm{MeOH}-\mathrm{H}_{2} \mathrm{O}-\mathrm{HOAc}(90: 9: 1, v / v)$, the extract was evaporated and injected into liquid chromatography-electrospray ionization tandem mass spectrometry system (API 2000; AB SCIEX, United States of America (USA)). Standards of SA >99\% (Fluka, Buchs, Switzerland) was made by diluting the standard solutions with the initial LC mobile phase $\left(0.05 \% \mathrm{HOAc}\right.$ in $\mathrm{H}_{2} \mathrm{O}-\mathrm{MeCN}$, $85: 15, v / v$ ). SA quantitation was analyzed using the standard addition method of SA solutions (range of 50 to $1000 \mathrm{ng} / \mathrm{mL}$ ). SA concentrations were calculated according to the detection results. 


\subsection{Histological Observation of Fungal Growth}

P. brachypodii growth and development in mutant or wild type plants were characterized by histopathological analysis. Inoculated leaves were sampled at $48 \mathrm{~h}$ and $120 \mathrm{~h}$, and leaves were treated and stained as previously described [25]. In brief, leaves were cut to $1.5 \mathrm{~cm}$ segments, which were fixed and decolorized in ethanol/trichloromethane (3:1 v/v) containing $0.15 \%(w / v)$ trichloroacetic acid for 3-5 days. For microscopic observation, leaves were treated and stained with WGA (wheat germ agglutinin conjugated to Alexa-488) (Invitrogen., Carlsbad, CA, USA). The lesion area and length were observed by an Olympus BX-53 microscope (Olympus Corp., Tokyo, Japan) and measured using CellScan Entry software. At least 30 randomly selected infection sites were measured, and 5 segments were randomly selected per treatment. Statistical analysis was performed using IBM SPSS 19 software (SPSS Inc., Chicago, IL, USA) with standard deviations and Tukey's test.

\subsection{PCR Analysis}

qRT-PCR reactions of $25 \mu \mathrm{L}$ included $25 \mathrm{ng}$ cDNA, $10 \mu \mathrm{L}$ Taq Mix and $0.5 \mu \mathrm{M}$ of each primer. PCR conditions were as follows: $95^{\circ} \mathrm{C}$ for $1 \mathrm{~min}, 30$ times $\left(95^{\circ} \mathrm{C}\right.$ for $20 \mathrm{~s}, 58^{\circ} \mathrm{C}$ for $15 \mathrm{~s}$, and $72{ }^{\circ} \mathrm{C}$ for $1 \mathrm{~min}$ ), and $72{ }^{\circ} \mathrm{C}$ for $4 \mathrm{~min}$. To standardize the data, ubiquitin-conjugating enzyme 18 gene (UBC18) was the internal reference. qRT-PCR was performed using a 7500 Real-Time PCR System (Applied Biosystems). Electrophoresis was performed using a 1.5\% agarose gel. qRT-PCR data were analyzed by the comparative $2^{-\Delta \Delta C t}$ method [26].

\subsection{Biomass Analysis}

To estimate changes in fungal biomass, the DNA level of P. brachypodii EF1 was measured by quantitative PCR with the DNA level of reference gene B. distachyon EF1. Relative fungal growth was then calculated as a ratio $(P b-E F 1 / B d-E F 1)$ to reflect the amplification efficiency.

Supplementary Materials: The following are available online at http://www.mdpi.com/2223-7747/9/10/1316/s1, Figure S1: PCR detection of AtSAG101 in transgenic Brachypodium distachyon. The sequence was $2359 \mathrm{bp}$ (ORF sequence $1578 \mathrm{bp}$ + Vector sequence $781 \mathrm{bp}$ ). M, Molecular size marker; $\mathrm{H}_{1} \mathrm{H}_{2} \mathrm{O}$ blank control; PC, pU1301AtSAG101 vector positive control; WT, wild type plants; L2-1, L3-2 and L5-2: transgenic B. distachyon plants, Table S1: Primers for plasmid constructions and PCR.

Author Contributions: N.W. and N.S.: Conceptualization, Data curation, Writing-Original draft preparation. Z.T.: Data curation. X.W. and Z.K.: Resources, Reviewing and Editing. L.D.: Writing-Reviewing and Editing. B.W.: Conceptualization, Writing-Original draft preparation, Funding acquisition. All authors have read and agreed to the published version of the manuscript.

Funding: This study was supported by grants from the National Natural Science Foundation of China (31801721; 31672017), National Key Research and Development Project (2016YFD0300707), the Natural Science Foundation of Hunan Province, China (2020JJ5240), the Scientific Research Fund of Hunan Provincial Education Department (19B247), and the Youth Fund Project of Hunan Agricultural University (19QN31).

Conflicts of Interest: The authors have no conflicts of interest to declare.

\section{References}

1. Wang, Y.; Tyler, B.M.; Wang, Y. Defense and counter defense during plant-pathogenic Oomycete infection. Annu. Rev. Microbiol. 2019, 73, 1-30. [CrossRef] [PubMed]

2. Durner, J.; Shah, J.; Klessig, D.F. Salicylic acid and disease resistance in plants. Trends Plant Sci. 1997, 2, 266-274. [CrossRef]

3. Vlot, A.C.; Dempsey, D.M.A.; Klessig, D.F. Salicylic acid, a multifaceted hormone to combat disease. Annu. Rev. Phytopathol. 2009, 47, 177-206. [CrossRef] [PubMed]

4. Feys, B.J.; Moisan, L.J.; Newman, M.A.; Parker, J.E. Direct interaction between the Arabidopsis disease resistance signaling proteins, EDS1 and PAD4. EMBO J. 2001, 20, 5400-5411. [CrossRef]

5. Feys, B.J.; Wiermer, M.; Bhat, R.A.; Moisan, L.J.; Medina-Escobar, N.; Neu, C.; Cabral, A.; Parker, J.E. Arabidopsis SENESCENCE-ASSOCIATED GENE101 stabilizes and signals within an ENHANCED DISEASE SUSCEPTIBILITY1 complex in plant innate immunity. Plant Cell 2005, 17, 2601-2613. [CrossRef] [PubMed] 
6. Zhu, S.; Jeong, R.D.; Venugopal, S.C.; Lapchyk, L.; Navarre, D.; Kachroo, A.; Kachroo, P. SAG101 forms a ternary complex with EDS1 and PAD4 and is required for resistance signaling against turnip crinkle virus. PLoS Pathog. 2011, 7, e1002318. [CrossRef] [PubMed]

7. Gantner, J.; Ordon, J.; Kretschmer, C.; Guerois, R.; Stuttmann, J. An EDS1-SAG101 Complex is Essential for TNL-mediated Immunity in Nicotiana benthamiana. Plant Cell 2019, 31, 2456-2474. [CrossRef]

8. Yu, S.; Tian, L. Breeding Major Cereal Grains through the Lens of Nutrition Sensitivity. Mol. Plant 2018, 11, 23-30. [CrossRef]

9. Garvin, D.F.; Gu, Y.Q.; Hasterok, R.; Hazen, S.P.; Jenkins, G.; Mockler, T.C.; Mur, L.A.; Vogel, J.P. Development of genetic and genomic research resources for Brachypodium distachyon, a new model system for grass crop research. Crop Sci. 2008, 48, S-69. [CrossRef]

10. Draper, J.; Mur, L.A.; Jenkins, G.; Ghosh-Biswas, G.C.; Bablak, P.; Hasterok, R.; Routledge, A.P. Brachypodium distachyon. A new model system for functional genomics in grasses. Plant Physiol. 2001, 127, 1539-1555. [CrossRef]

11. Dean, R.; Van Kan, J.A.; Pretorius, Z.A.; Hammond-Kosack, K.E.; Di Pietro, A.; Spanu, P.D.; Rudd, J.J.; Dickman, M.; Kahmann, R.; Ellis, J.; et al. The Top 10 fungal pathogens in molecular plant pathology. Mol. Plant Pathol. 2012, 13, 414-430. [CrossRef] [PubMed]

12. Fitzgerald, T.L.; Powell, J.J.; Schneebeli, K.; Hsia, M.M.; Gardiner, D.M.; Bragg, J.N.; McIntyre, C.L.; Manners, J.M.; Ayliffe, M.; Watt, M.; et al. Brachypodium as an emerging model for cereal-pathogen interactions. Ann. Bot. 2015, 115, 717-731. [CrossRef] [PubMed]

13. Parker, D.; Beckmann, M.; Enot, D.P.; Overy, D.P.; Rios, Z.C.; Gilbert, M.; Talbot, N.; Draper, J. Rice blast infection of Brachypodium distachyon as a model system to study dynamic host/pathogen interactions. Nat. Protoc. 2008, 3, 435. [CrossRef]

14. Zambino, P.J.; Szabo, L.J. Phylogenetic relationships of selected cereal and grass rusts based on rDNA sequence analysis. Mycologia 1993, 85, 401-414. [CrossRef]

15. Joglekar, S.; Suliman, M.; Bartsch, M.; Halder, V.; Maintz, J.; Bautor, J.; Zeier, J.; Parker, J.E.; Kombrink, E. Chemical activation of EDS1/PAD4 signaling leading to pathogen resistance in Arabidopsis. Plant Cell Physiol. 2018, 59, 1592-1607. [CrossRef]

16. Zhou, N.; Tootle, T.L.; Tsui, F.; Klessig, D.F.; Glazebrook, J. PAD4 functions upstream from salicylic acid to control defense responses in Arabidopsis. Plant Cell 1998, 10, 1021-1030. [CrossRef] [PubMed]

17. Collier, S.M.; Hamel, L.P.; Moffett, P. Cell death mediated by the N-terminal domains of a unique and highly conserved class of NB-LRR protein. Mol. Plant-Microbe Interact. 2011, 24, 918-931. [CrossRef] [PubMed]

18. Cui, H.; Gobbato, E.; Kracher, B.; Qiu, J.; Bautor, J.; Parker, J.E. A core function of EDS1 with PAD4 is to protect the salicylic acid defense sector in Arabidopsis immunity. New Phytol. 2017, 213, 1802-1817. [CrossRef]

19. Lapin, D.; Kovacova, V.; Sun, X.; Dongus, J.A.; Bhandari, D.; von Born, P.; Bautor, J.; Guarneri, N.; Rzemieniewski, J.; Stuttmann, J.; et al. A coevolved EDS1-SAG101-NRG1 module mediates cell death signaling by TIR-domain immune receptors. Plant Cell 2019, 31, 2430-2455. [CrossRef]

20. Jirage, D.; Tootle, T.L.; Reuber, T.L.; Frost, L.N.; Feys, B.J.; Parker, J.E.; Ausubel, F.M.; Glazebrook, J. Arabidopsis thaliana PAD4 encodes a lipase-like gene that is important for salicylic acid signaling. Proc. Natl. Acad. Sci. USA 1999, 96, 13583-13588. [CrossRef]

21. Lipka, V.; Dittgen, J.; Bednarek, P.; Bhat, R.; Wiermer, M.; Stein, M.; Landtag, J.; Brandt, W.; Rosahl, S.; Scheel, D.; et al. Pre-and postinvasion defenses both contribute to nonhost resistance in Arabidopsis. Science 2005, 310, 1180-1183. [CrossRef] [PubMed]

22. Wang, B.; Wang, N.; Song, N.; Wang, W.; Wang, J.; Wang, X.; Kang, Z. Overexpression of AtPAD4 in transgenic Brachypodium distachyon enhances resistance to Puccinia brachypodii. Plant Biol. 2017, 19, 868-874. [CrossRef] [PubMed]

23. Vogel, J.P.; Garvin, D.F.; Leong, O.M.; Hayden, D.M. Agrobacterium-mediated transformation and inbred line development in the model grass Brachypodium distachyon. Plant Cell Tissue Organ Cult. 2006, 84, 199-211. [CrossRef]

24. Sundaresan, V.; Springer, P.; Volpe, T.; Haward, S.; Jones, J.D.; Dean, C.; Ma, H.; Martienssen, R. Patterns of gene action in plant development revealed by enhancer trap and gene trap transposable elements. Genes Dev. 1995, 9, 1797-1810. [CrossRef] [PubMed] 
25. Segarra, G.; Jáuregui, O.; Casanova, E.; Trillas, I. Simultaneous quantitative LC-ESI-MS/MS analyses of salicylic acid and jasmonic acid in crude extracts of Cucumis sativus under biotic stress. Phytochemistry 2006, 67, 395-401. [CrossRef]

26. Livak, K.J.; Schmittgen, T.D. Analysis of relative gene expression data using real-time quantitative PCR and the $2^{-\Delta \Delta \mathrm{CT}}$ method. Methods 2001, 25, 402-408. [CrossRef] [PubMed]

(C) 2020 by the authors. Licensee MDPI, Basel, Switzerland. This article is an open access article distributed under the terms and conditions of the Creative Commons Attribution (CC BY) license (http://creativecommons.org/licenses/by/4.0/). 